\title{
Gas-Phase Deposition of Gold Nanoclusters to Produce Heterogeneous Glycerol Oxidation Catalysts
}

\author{
Rongsheng Cai, Grazia Malta, Sarah J. Haigh, Graham J. Hutchings, Simon J. Freakley,*
} and Richard E. Palmer*

Cite This: ACS Appl. Nano Mater. 2020, 3, 4997-5001

Read Online

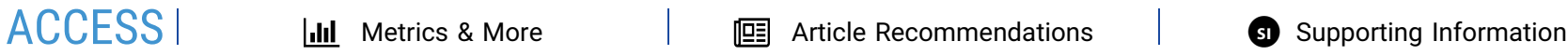

ABSTRACT: Gold nanoparticles prepared by colloidal methods are effective catalysts for selective glycerol oxidation under basic conditions. Large-scale synthesis of catalysts by wet chemical methods leads to large amounts of waste and can result in polymer or salt residues remaining on the catalyst. In contrast, gas-phase cluster deposition (cluster beam deposition) offers a solvent-free method to synthesize controlled nanoparticles/clusters. We show that the deposition of bare gas-phase gold clusters onto carbon powder leads to a catalyst comparable to that prepared by colloidal methods. This shows the feasibility of the synthesis method to produce oxidation catalysts with reduced waste.

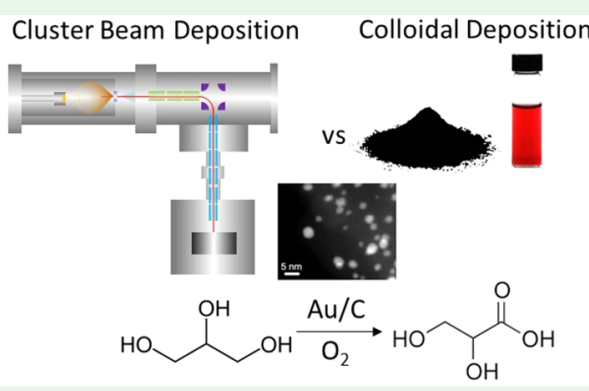

KEYWORDS: gold, colloidal, cluster, cluster beam deposition, glycerol, oxidation

$\mathrm{T}$ he selective oxidation of glycerol, a byproduct of biodiesel production, represents a large-scale route to biomass upgrading and a model for selective polyol oxidation (Scheme 1a). ${ }^{1,2}$ Supported gold nanoparticles prepared by wet chemical methods, such as incipient-wetness impregnation and deposition precipitation, can be effective catalysts for glycerol

Scheme 1. (a) Reaction Scheme Showing Possible Glycerol Oxidation Pathways and Schematic Representations of Catalyst Fabrication Methods via (b) Immobilization of Gold Colloids and (c) CBD

a)

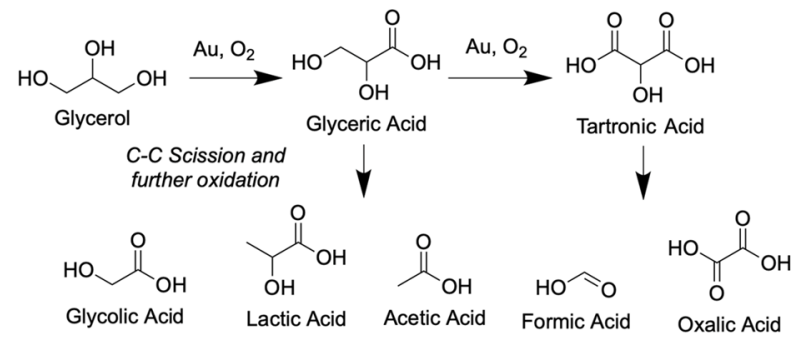

b) $\mathrm{HAuCl}_{4(\text { (aq.) }}+\mathrm{PVP}+\mathrm{NaBH}_{4}$

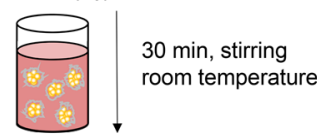

Au-PVP Colloids (2-4 nm)

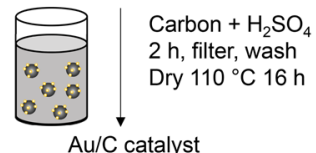

c)

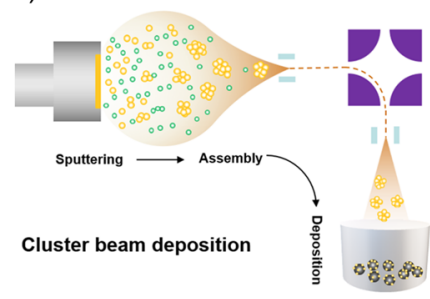

oxidation. ${ }^{3}$ Gold catalysts can achieve high selectivity to $\mathrm{C}_{3}$ products (glycerate and tartronate) under basic conditions with low rates of $\mathrm{C}-\mathrm{C}$ scission compared to oxidation catalysts containing palladium or platinum.,

An alternative method to produce catalysts containing metal nanoparticles $(2-5 \mathrm{~nm})$ is the immobilization of colloidal gold particles onto activated carbon (Scheme 1b). This approach involves the rapid reduction of a gold precursor using $\mathrm{NaBH}_{4}$ to initiate colloid formation with polymer additives such as poly(vinylpyrrolidone) (PVP) providing steric stabilization. ${ }^{6,7}$ The synthesis of catalysts prepared in this way can produce aqueous waste containing chlorides and residual salts because of the low gold concentrations needed to stabilize small gold particles. In addition, catalysts prepared in this manner typically retain polymer residues on the gold surface, which can potentially be removed by high-temperature oxidative treatments or washing with a suitable solvent, leading to possible particle agglomeration or leaching. ${ }^{8,9}$ These residues can affect the reaction pathways and catalyst activity through interaction with the substrate or blocking of active sites. Recently, the preparation of catalysts with similar glycerol oxidation activity in the absence of polymer stabilizers was demonstrated; however, the absence of a polymer additive led

Received: April 27, 2020

Accepted: May 28, 2020

Published: May 28, 2020 

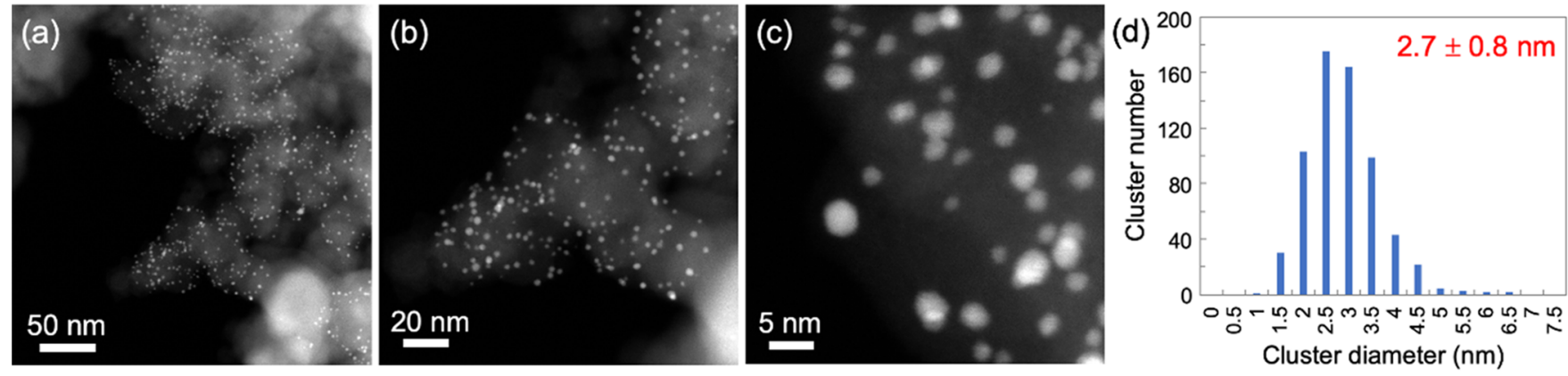

Figure 1. $(\mathrm{a}-\mathrm{c})$ Typical HAADF-STEM images (with different magnifications) of Au/C prepared by colloidal methods. (d) Cluster size distribution histogram with a mean particle size of $2.7 \pm 0.8 \mathrm{~nm}$.
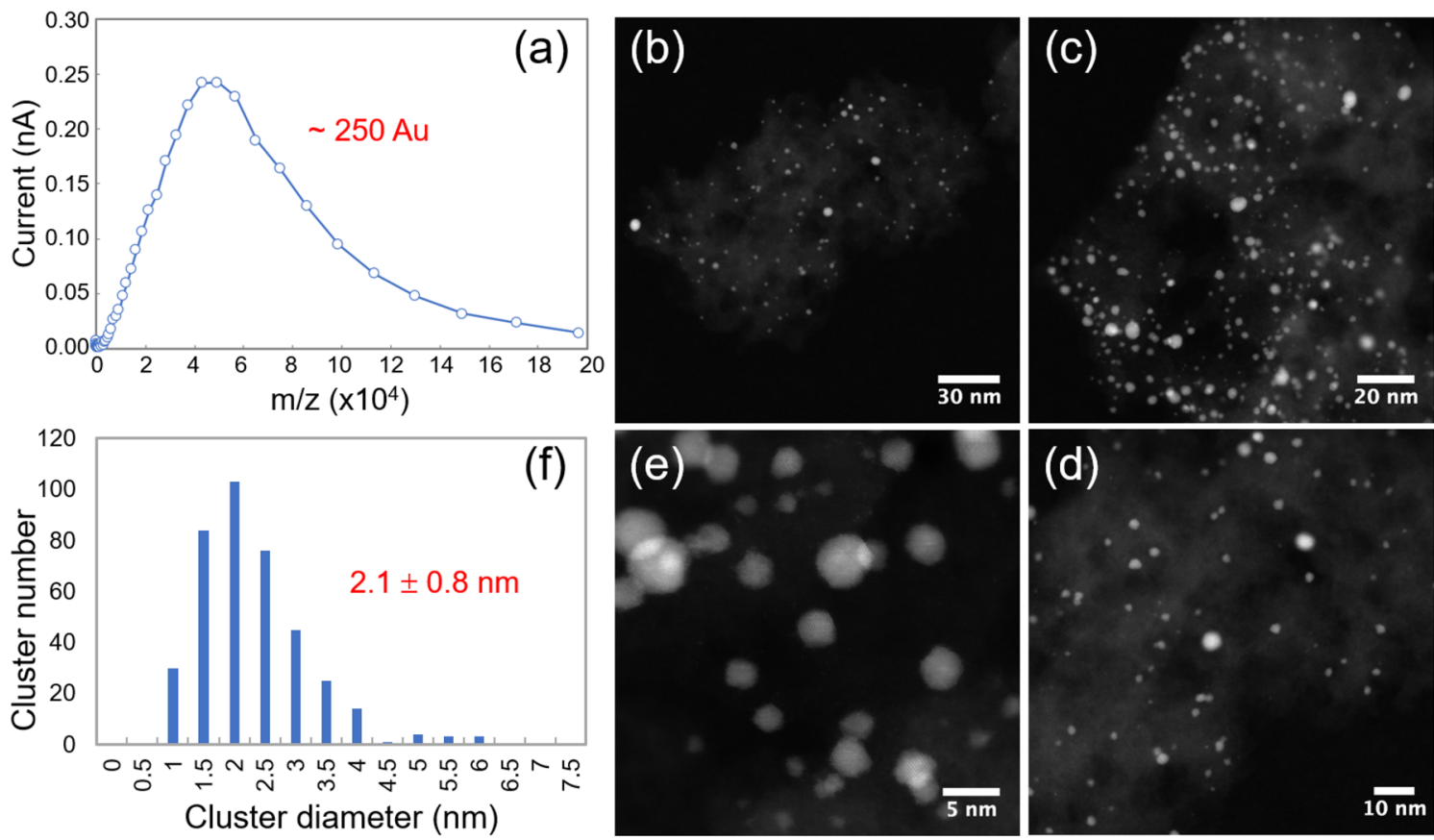

Figure 2. (a) Gas-phase cluster mass spectrum obtained during the deposition procedure. (b-e) Typical HAADF STEM images (with different magnifications) of the $\mathrm{Au} / \mathrm{C}$ catalyst prepared by $\mathrm{CBD}$. (f) Cluster size distribution histogram with a mean particle size of $2.1 \pm 0.8 \mathrm{~nm}$.

to an increase in selectivity toward tartronate versus the primary oxidation product glycerate. ${ }^{10}$

It is highly desirable to develop catalyst manufacturing methods that produce less waste and give control over the metal particle size without residues remaining on the catalyst surface. The deposition of pregrown metallic gold clusters from the gas phase onto powder supports can achieve this. ${ }^{11,12}$ Metallic materials can be vaporized by methods such as magnetron sputtering and then condensed in rare gas to form a cluster beam that can be deposited onto supports. As the clusters are formed in an ultrahigh-vacuum chamber, they are produced without detrimental contamination or residues. ${ }^{13}$ This approach is termed "cluster beam deposition" (CBD) (Scheme 1c). The mean cluster size can be tuned by the condensation parameters such as inert gas pressure and aggregation length. ${ }^{14}$ Moreover, by combination with a timeof-flight mass filter, single-atom precision can be achieved, which allows controlled exploration of the size-dependent nanoparticle properties. ${ }^{15-17}$

To compare this new CBD method with commonly used colloidal methods, we aimed to prepare analogous carbonsupported gold nanoparticle materials ( $1 \mathrm{wt} \% \mathrm{Au} / \mathrm{C}$ ) and compare the performance for glycerol oxidation under basic conditions. Detailed experimental procedures for catalyst preparation, testing, and characterization are available in the Supporting Information. A colloidal catalyst was prepared using the commonly reported literature procedure, with $\mathrm{NaBH}_{4}$ as the reductant $\left(\mathrm{NaBH}_{4} / \mathrm{Au}=5\right.$ by mole $)$ and PVP $(\mathrm{PVP} / \mathrm{Au}=0.65$ by weight $)$ as the steric stabilizer. ${ }^{10}$ The colloid was subsequently immobilized on a high-surface carbon (Vulcan XC72R; $250 \mathrm{~m}^{2} / \mathrm{g}$ ), washed, and dried $\left(110^{\circ} \mathrm{C} 16 \mathrm{~h}\right.$ ) without high-temperature oxidative treatments to combust the remaining polymer residues from the catalyst surface. The $1 \mathrm{wt}$ $\% \mathrm{Au} / \mathrm{C}$ prepared by colloidal methods on a $2 \mathrm{~g}$ scale was characterized by scanning transmission electron microscopy (STEM) in high-angle annular dark-field (HAADF) mode, which shows gold nanoparticles on the carbon support with a mean particle size of $2.7 \pm 0.8 \mathrm{~nm}$, as seen in Figure 1 , and is consistent with previous reports. ${ }^{10}$

CBD was employed to deposit gold clusters onto the same carbon powder support. Detailed information about the magnetron sputtering gas condensation CBD equipment can be found in a previous report. ${ }^{18}$ By tuning of the sputtering power and pressure in the condensation chamber, small gas- 

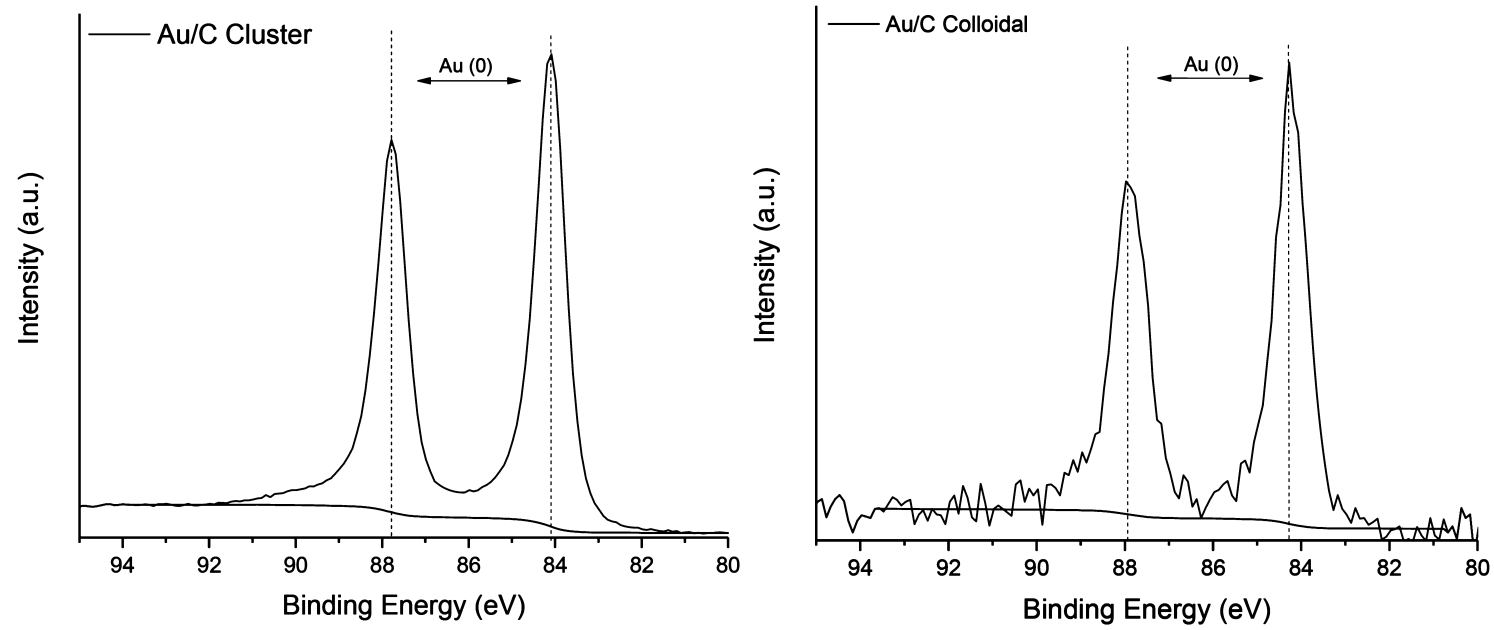

Figure 3. Au 4f XPS spectra of freshly prepared Au/C by cluster deposition and colloidal methods.

phase gold clusters $(\sim 2 \mathrm{~nm})$ were produced in a vacuum chamber before acceleration and deposition (without mass selection) onto carbon powder being agitated in a stainlesssteel cup. The cluster mass distribution (mass spectrum) was obtained with a time-of-flight mass filter shown in Figure 2a. The main cluster peak is located at $\sim 5 \times 10^{4} \mathrm{amu}$, which is equivalent to a gold cluster containing $\sim 250$ atoms $\left(\mathrm{Au}_{250}\right)$. On the basis of the bulk density of gold, the cluster diameter at the peak assuming a spherical shape can be calculated to be $\sim 1.9 \mathrm{~nm}$. To clarify whether the clusters retain their size after deposition, HAADF-STEM imaging was employed to obtain the corresponding diameter distribution. Parts $\mathrm{b}-\mathrm{e}$ of Figure 2 show typical HAADF-STEM images with different magnifications. Clearly, a dense array of gold clusters is observed on the support without severe surface aggregation. The cluster diameter distribution in Figure $2 \mathrm{f}$ shows that most of the clusters have a diameter of $2.1 \pm 0.8 \mathrm{~nm}$, similar to the calculated cluster diameter. Therefore, no severe surface aggregation took place during the deposition process.

X-ray photoemission spectroscopy (XPS) characterization of the sample prepared by $\mathrm{CBD}$ methods was carried out to determine the oxidation state of the metal clusters deposited. XPS consistent with the $\mathrm{Au} 4 \mathrm{f}_{7 / 2}$ binding energy of metallic gold nanoparticles was observed at $84.1 \mathrm{eV}$ and is shown Figure 3. This supports the hypothesis that the material is an analogue of the colloidal catalyst, which contains metallic gold nanoparticles following synthesis in the presence of a strong reductant (Figure 3). ${ }^{19,20}$ The metal loading of the CBD sample was determined by inductively coupled plasma mass spectrometry (ICP-MS) after acid digestion to be $0.17 \mathrm{wt} \%$. This was lower than the target $0.3-0.5 \mathrm{wt} \%$, likely because of deposition of a portion of the clusters onto the vibration cup or charging of the deposition cup under the ion beam, which can lead to deflection of the clusters prior to deposition. The sample prepared by colloidal methods had a gold loading of 1.21 wt $\%$. We also found a high particle deposition density on some grains of carbon on samples prepared by CBD (Figure 4) compared with others with little gold deposition. This likely occurs because of inadequate powder agitation by the vibration cup. Despite this, significant particle agglomeration was not observed, as evidenced by representative STEM images (Figure 2) and repeatable catalytic results over multiple experiments. This observation, in addition to the smaller gold particle size, also accounts for the different signal-to-noise

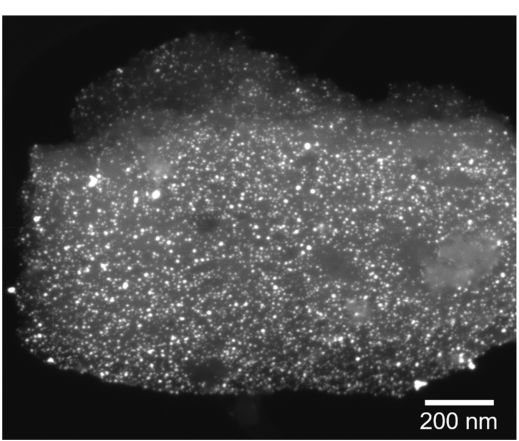

Figure 4. SEM image of a carbon particle with a high density of gold particle deposition prepared by CBD methods.

ratios in the XPS spectra. Because both preparation methods deposit preformed gold particles, we consider that the particle size will not change substantially as a function of the metal loading of the two samples, and therefore a comparison of the two samples is possible when normalized to take into account active gold surfaces determined by particle size distribution.

Both samples were tested for glycerol oxidation (Table 1) under basic conditions at $60^{\circ} \mathrm{C}$ and 3 bar of $\mathrm{O}_{2}$ pressure. After

Table 1. Comparison of Colloidal- and Cluster-Deposited $\mathrm{Au} / \mathrm{C}$ Catalyst Activities toward Glycerol Oxidation ${ }^{a}$

$\begin{array}{ccccc}\text { catalyst } & \begin{array}{c}\text { gold } \\ \text { content } \\ (\text { wt } \%)\end{array} & \begin{array}{c}\text { catalyst } \\ \text { mass } \\ (\mathrm{mg})\end{array} & \begin{array}{c}\text { conversion } \\ (\%)\end{array} & \begin{array}{c}\mathrm{TON}(\mathrm{mol} \text { of } \\ \mathrm{GL} Y_{\text {converted }} / \mathrm{mol} \text { of } \\ \text { Au }\end{array} \\ \begin{array}{c}\mathrm{Au} / \mathrm{C} \text { colloid } \\ \text { deposition }\end{array} & 1.21 & 10 & 95 & 4610 \\ \begin{array}{c}\mathrm{Au} / \mathrm{C} \text { cluster } \\ \text { deposition }\end{array} & 0.17 & 20 & 52 & 8990\end{array}$

${ }^{a}$ Reaction conditions: $10 \mathrm{~mL}$ of glycerol $(0.3 \mathrm{M})$ and $\mathrm{NaOH}(0.6 \mathrm{M})$, $4 \mathrm{~h}, 60{ }^{\circ} \mathrm{C}, 3 \mathrm{bar}$ of $\mathrm{O}_{2}, 1200 \mathrm{rpm}$

$4 \mathrm{~h}$ of reaction, glycerol conversion for the sample prepared by colloidal methods reached $95 \%$ when $10 \mathrm{mg}$ of catalyst was used, with glycerate the major product observed (55\% selectivity). In addition, significant amounts of tartronate (10\% selectivity), resulting from the further oxidation of glycerate, and glycolate ( $15 \%$ selectivity), resulting from $\mathrm{C}-\mathrm{C}$ scission, were observed. Selectivity profiles are reported in Table 2. The remaining reaction products included oxalate, 
Table 2. Selectivity for Glycerol Oxidation Using Colloidaland Cluster-Deposited Au/C Catalysts ${ }^{a}$

\begin{tabular}{lcc} 
& \multicolumn{2}{c}{ selectivity $(\%)$} \\
\cline { 2 - 3 } oxalate & Au/C colloidal & $\mathrm{Au} / \mathrm{C}$ cluster \\
tartronate & 2 & 1 \\
glycerate & 10 & 3 \\
glycolate & 55 & 64 \\
lactate & 16 & 19 \\
pyruvate & 8 & 6 \\
formate & 0 & 0 \\
acetate & 7 & 8 \\
\hline
\end{tabular}

${ }^{a}$ Reaction conditions: $10 \mathrm{~mL}$ of glycerol $(0.3 \mathrm{M})$ and $\mathrm{NaOH}(0.6 \mathrm{M})$, $4 \mathrm{~h}, 60{ }^{\circ} \mathrm{C}, 3 \mathrm{bar}$ of $\mathrm{O}_{2}, 1200 \mathrm{rpm}$.

lactate, acetate, and formate, with selectivities below $10 \%$. Because of the lower metal loading, the catalyst prepared by CBD was tested at higher catalyst mass $(20 \mathrm{mg})$ over the same $4 \mathrm{~h}$ reaction time. The sample achieved significant glycerol conversion (52\%). Despite the differences in the conversion levels, the $\mathrm{CBD}$ catalyst showed similar selectivity trends, with a selectivity of $64 \%$ to glycerate as the main reaction product. The lower selectivity to tartronate (3\%) and higher selectivity to glycerate are consistent with lower glycerol conversion and reduced overoxidation of the glycerate produced in the presence of the remaining glycerol. This is consistent with previous studies showing that product selectivity remains constant over a wide range of glycerol conversion until glycerol is fully consumed. ${ }^{10}$

Comparing the turnover number (TON) for glycerol conversion between the catalysts prepared by colloidal and CBD methods demonstrates that the sample prepared by cluster deposition has around twice the glycerol conversion per mole of gold (Table 1) over the reaction time. Moreover, the particle size determined by STEM for the gold clusters in the colloidal sample $(2.7 \mathrm{~nm})$ is slightly larger than that for the CBD samples $(2.1 \mathrm{~nm})$. On the basis of a surface area calculation assuming spherical particles, the total surface area, $S$, is proportional to $1 / d(d=$ cluster diameter $)$. Therefore, the total surface area ratio for these two samples, $S_{\text {cluster deposition of gold }} / S_{\text {colloidal deposition of gold, }}$ is around $1.3: 1$ based on their mean particle size. This suggests that additional factors, such as the absence of polymer residue at the nanoparticle surface or enhanced activity on smaller structures, could contribute to higher glycerol conversion per mole of gold. This indicates that, on average, surface atoms of the CBD clusters are more active than the colloidal clusters within our approximation. Although further work is needed to fully disclose the effect of chemical ligands (PVP in this case) on the reaction kinetics, these results demonstrate that the $\mathrm{CBD}$ method can produce catalysts with activities at least similar to those produced by colloidal routes.

The high glycerol conversions observed per mole of gold demonstrate that effective catalysts for liquid-phase oxidation can be prepared by the deposition of gas-phase clusters. Moreover, the ability to stabilize smaller particle sizes in the absence of residual contaminant such as polymers on the metal particles should be beneficial for catalysis and is an advantage of the CBD approach over wet chemical methods. Our future studies will further explore the performance of this class of catalysts compared with colloidally prepared materials, in terms of activity, selectivity, and stability for a range of catalytic reactions.

\section{ASSOCIATED CONTENT}

\section{Supporting Information}

The Supporting Information is available free of charge at https://pubs.acs.org/doi/10.1021/acsanm.0c01140.

Additional experimental details (PDF)

\section{AUTHOR INFORMATION}

\section{Corresponding Authors}

Simon J. Freakley - Department of Chemistry, University of Bath, Bath BA2 7AY, U.K.; 이이.org/0000-0002-63956646; Email: s.freakley@bath.ac.uk

Richard E. Palmer - College of Engineering, Swansea University, Swansea SA1 8EN, U.K.; † orcid.org/0000-0001-87288083; Email: r.e.palmer@swansea.ac.uk

\section{Authors}

Rongsheng Cai - College of Engineering, Swansea University, Swansea SA1 8EN, U.K.; $\odot$ orcid.org/0000-0002-2148-0563

Grazia Malta - Cardiff Catalysis Institute, Cardiff University, Cardiff CF10 3AT, U.K.

Sarah J. Haigh - Department of Materials, The University of Manchester, Manchester M13 9PL, U.K.; 이이이.org/00000001-5509-6706

Graham J. Hutchings - Cardiff Catalysis Institute, Cardiff University, Cardiff CF10 3AT, U.K.; 10 orcid.org/0000-00018885-1560

Complete contact information is available at:

https://pubs.acs.org/10.1021/acsanm.0c01140

\section{Notes}

The authors declare no competing financial interest.

\section{ACKNOWLEDGMENTS}

We thank Dr. David Morgan for the acquisition of XPS spectra and Dr. Jinlong Yin and Giuseppe Sanzone for assistance provided during the sample preparation. R.C. and S.J.H. are thankful for support from the Engineering and Physical Sciences Research Council (Grant EP/P009050/1).We are thankful for financial support from the EPSRC (Grant Reference No. EP/K006061/2) and the European Union's Horizon 2020 programme through the CritCat project under Grant Agreement No. 686053.

\section{REFERENCES}

(1) Dodekatos, G.; Schünemann, S.; Tüysüz, H. Recent Advances in Thermo-, Photo-, and Electrocatalytic Glycerol Oxidation. ACS Catal. 2018, 8 (7), 6301-6333.

(2) Villa, A.; Dimitratos, N.; Chan-Thaw, C. E.; Hammond, C.; Prati, L.; Hutchings, G. J. Glycerol oxidation using gold-containing catalysts. Acc. Chem. Res. 2015, 48 (5), 1403-1412.

(3) Prati, L.; Villa, A. The Art of Manufacturing Gold Catalysts. Catalysts 2012, 2 (1), 24-37.

(4) Carrettin, S.; McMorn, P.; Johnston, P.; Griffin, K.; Hutchings, G. J. Selective oxidation of glycerol to glyceric acid using a gold catalyst in aqueous sodium hydroxide. Chem. Commun. 2002, No. 7, 696-697.

(5) Porta, F.; Prati, L. Selective oxidation of glycerol to sodium glycerate with gold-on-carbon catalyst: an insight into reaction selectivity. J. Catal. 2004, 224 (2), 397-403. 
(6) Villa, A.; Wang, D.; Veith, G. M.; Vindigni, F.; Prati, L. Sol immobilization technique: a delicate balance between activity, selectivity and stability of gold catalysts. Catal. Sci. Technol. 2013, 3 (11), 3036-3041.

(7) Rogers, S. M.; Catlow, C. R. A.; Chan-Thaw, C. E.; Gianolio, D.; Gibson, E. K.; Gould, A. L.; Jian, N.; Logsdail, A. J.; Palmer, R. E.; Prati, L.; Dimitratos, N.; Villa, A.; Wells, P. P. Tailoring Gold Nanoparticle Characteristics and the Impact on Aqueous-Phase Oxidation of Glycerol. ACS Catal. 2015, 5 (7), 4377-4384.

(8) Lopez-Sanchez, J. A.; Dimitratos, N.; Hammond, C.; Brett, G. L.; Kesavan, L.; White, S.; Miedziak, P.; Tiruvalam, R.; Jenkins, R. L.; Carley, A. F.; Knight, D.; Kiely, C. J.; Hutchings, G. J. Facile removal of stabilizer-ligands from supported gold nanoparticles. Nat. Chem. 2011, 3 (7), 551-556.

(9) Donoeva, B.; de Jongh, P. E. Colloidal Au Catalyst Preparation: Selective Removal of Polyvinylpyrrolidone from Active Au Sites. ChemCatChem 2018, 10 (5), 989-997.

(10) Abis, L.; Dimitritatos, N.; Sankar, M.; Freakley, S. J.; Hutchings, G. J. The Effect of Polymer Addition on Base Catalysed Glycerol Oxidation Using Gold and Gold-Palladium Bimetallic Catalysts. Top. Catal. 2019, DOI: 10.1007/s11244-019-01212-y.

(11) Ayodele, O. B.; Cai, R.; Wang, J.; Ziouani, Y.; Liang, Z.; Spadaro, M. C.; Kovnir, K.; Arbiol, J.; Akola, J.; Palmer, R. E.; Kolen'ko, Y. V. Synergistic Computational-Experimental Discovery of Highly Selective PtCu Nanocluster Catalysts for Acetylene Semihydrogenation. ACS Catal. 2020, 10 (1), 451-457.

(12) Cai, R.; Cao, L.; Griffin, R.; Chansai, S.; Hardacre, C.; Palmer, R. E. Scale-up of cluster beam deposition to the gram scale with the matrix assembly cluster source for heterogeneous catalysis (propylene combustion). AIP Adv. 2020, 10 (2), 025314.

(13) Palmer, R. E.; Cai, R.; Vernieres, J. Synthesis without Solvents: The Cluster (Nanoparticle) Beam Route to Catalysts and Sensors. Acc. Chem. Res. 2018, 51 (9), 2296-2304.

(14) Plant, S. R.; Cao, L.; Palmer, R. E. Atomic structure control of size-selected gold nanoclusters during formation. J. Am. Chem. Soc. 2014, 136 (21), 7559-7562.

(15) Pratontep, S.; Carroll, S. J.; Xirouchaki, C.; Streun, M.; Palmer, R. E. Size-selected cluster beam source based on radio frequency magnetron plasma sputtering and gas condensation. Rev. Sci. Instrum. 2005, 76 (4), 045103.

(16) Vajda, S.; White, M. G. Catalysis Applications of Size-Selected Cluster Deposition. ACS Catal. 2015, 5 (12), 7152-7176.

(17) Tyo, E. C.; Vajda, S. Catalysis by clusters with precise numbers of atoms. Nat. Nanotechnol. 2015, 10 (7), 577-588.

(18) Cai, R.; Ellis, P. R.; Yin, J.; Liu, J.; Brown, C. M.; Griffin, R.; Chang, G.; Yang, D.; Ren, J.; Cooke, K.; Bishop, P. T.; Theis, W.; Palmer, R. E. Performance of Preformed $\mathrm{Au} / \mathrm{Cu}$ Nanoclusters Deposited on $\mathrm{MgO}$ Powders in the Catalytic Reduction of 4Nitrophenol in Solution. Small 2018, 14 (13), 1703734.

(19) Casaletto, M. P.; Longo, A.; Martorana, A.; Prestianni, A.; Venezia, A. M. XPS study of supported gold catalysts: the role of Au0 and $\mathrm{Au}+\delta$ species as active sites. Surf. Interface Anal. 2006, 38 (4), 215-218.

(20) von Issendorff, B.; Palmer, R. E. A new high transmission infinite range mass selector for cluster and nanoparticle beams. Rev. Sci. Instrum. 1999, 70 (12), 4497-4501. 